\title{
Tumores de Células Germinativas Testiculares: Casuística do Hospital CUF Infante Santo
}

\section{Testicular Germ Cell Tumours: Casuistics in Hospital CUF Infante Santo}

Orlando Nunes¹, Manuela Bernardo¹, Leonor Ribeiro ${ }^{1}$, António Cabeças², Fernando Ferrito ${ }^{2}$, Cabrita Carneiro², Rui Nogueira ${ }^{3}$, Paulo Vale ${ }^{3}$

\section{RESUMO}

INTRODUÇÃO: Os tumores de células germinativas são tumores raros, constituindo 1\% a 2\% do total das neoplasias malignas e cerca de $5 \%$ do total dos tumores malignos urológicos. Originam-se no testículo em mais de $90 \%$ dos casos.

MÉTODOS: Os autores reveem os casos de tumores de células germinativas, incluindo o diagnóstico, tratamento e follow-up, ocorridos no Hospital CUF Infante Santo num período de mais de 15 anos, compreendido entre agosto de 1999 e novembro de 2014.

RESULTADOS: A série compreende 33 doentes, todos submetidos inicialmente a orquidectomia radical, diagnóstica e terapêutica, estando o maior número de doentes, 21 (63,6\%) em estádio I. Destes, 14 (66\% dos estádios I), vieram a fazer tratamento pós-orquidectomia. Todos os doentes em estádios mais avançados efetuaram tratamento pós-cirúrgico. Verificaram-se apenas quatro recidivas (12,1\%), ocorridas em mediana 20 meses pós-diagnóstico e todas salvas por posterior tratamento.

CONCLUSÃO: A toxicidade parece-nos aceitável, não tendo ocorrido nenhuma morte relacionada com qualquer modalidade de tratamento.

Com uma mediana de follow-up de 59 meses à data da conclusão da revisão, a sobrevivência livre de doença foi de $100 \%$.

PALAVRAS-CHAVE: Estudos de Seguimento; Neoplasias Embrionárias de Células Germinativas; Neoplasias Testiculares; Recidiva Local de Neoplasia/diagnóstico 


\section{ABSTRACT}

INTRODUCTION: Germ cell tumors are rare tumors, accounting for $1 \%$ to $2 \%$ of all malignancies and about $5 \%$ of all malignant urologic tumors. They originate in the testis in more than $90 \%$ of cases.

METHODS: The authors conduct a review of all cases of germ cell tumors, from diagnose and treatment till follow-up, treated in Hospital CUF Infante Santo comprising a period of more than 15 years, between 1999 August and 2014 November.

RESULTS: This series include 33 patients all of them submitted to diagnostic and therapeutic radical orchiectomy, with the majority of them in clinical stage I disease: 21 patients (63.6\%). Of this early stage patients, 14 (66\%), later received post surgical treatment. All the patients with more advanced stages where submitted to treatment post orchiectomy. There were four recurrences (12.1\%), at a median time of 20 months post diagnose and all of them achieved a second complete remission after treatment.

CONCLUSION: Overall the toxicity seems acceptable, not registering any death as a secondary effect of any kind of treatment. At the conclusion of this revue, with a median follow-up of 59 months, all patients were alive and free from disease. KEYWORDS: Follow-Up Studies; Follow-Up Studies, Neoplasms, Germ Cell and Embryonal; Neoplasm Recurrence, Local/ diagnosis; Testicular Neoplasms

\section{INTRODUÇÃO}

Os tumores de células germinativas (TCG) são tumores raros, constituindo $1 \%$ a $2 \%$ do total das neoplasias malignas e cerca de 5\% do total dos tumores malignos urológicos. Originam-se no testículo em mais de $90 \%$ dos casos, sendo raros TCG extra-gonadais, e neste caso o retroperitoneu e o mediastino, são os locais mais frequentemente envolvidos. . $^{1-3}$

Afetam quase sempre jovens adultos do sexo masculino com uma incidência maior na faixa etária dos 15 aos 34 anos, onde constituem o tumor sólido mais comum.

Têm origem nas células primitivas da espermatogénese, representando cerca de 95\% dos tumores do testículo, sendo os 5\% restantes representados por linfomas, tumores do estroma (células de Sertoli ou Leydig), ou metástases.

De acordo com o tipo histológico, subdividem-se em dois grandes grupos:

- Seminomas, com origem na célula germinativa mais primitiva e uma mediana de idade superior à data do diagnóstico;

- Não seminomas, contendo quase sempre diferentes tipos histológicos (yolk sac, teratoma, carcinoma embrionário e coriocarcinoma) em proporções variáveis e com uma mediana de idade inferior à data do diagnóstico.

O seminoma puro é o tipo histológico mais frequente (cerca de 40\% dos casos), sendo os restantes representados por não seminomas.

São apontados fatores de risco diversos. Entre os mais frequentemente referidos, estão a existência de história anterior de tumor de células germinativas (1\% a 2\% vêm a desenvolver um segundo tumor no testículo contralateral), história familiar de neoplasia de células germinativas e a criptorquidia (aumento de risco de $4 \%$ a 8\%). ${ }^{1-4}$

Algumas síndromes genéticas têm sido associadas a um aumento do risco, como é o caso da síndrome de Klinefelter $(47 \mathrm{XXY})$ e praticamente todos os adultos com TCG, têm um aumento de cópias do cromossoma 12 $\mathrm{i}(12 \mathrm{p}) \cdot{ }^{1-4}$

Do ponto de vista da apresentação clínica, é geralmente assintomático ou despertando uma sensação de peso/ incómodo. A existência de dor escrotal, não deve de nenhuma maneira e por si só excluir o diagnóstico de TCG. $\bigcirc$ doente nota quase sempre um aumento de volume ou nódulo do testículo que o leva ao médico. No exame físico, na ausência de doença metastática onde outros sinais podem também estar presentes, uma massa testicular palpável, que faz corpo com o testículo, é o sinal praticamente sempre presente, confirmando-se a existência da lesão intratesticular por ecografia escrotal que deve ser bilateral. Em caso de doença metastizada, a dor lombar associada a metastização ganglionar retroperitoneal ou sintomas respiratórios associados a envolvimento pulmonar, são frequentes. ${ }^{1-4}$

O estadiamento imagiológico para excluir doença metastizada compreende tomografia computorizada (TC) abdominal e pélvica e radiografia de tórax. As indicações para TC de tórax, sendo menos consensuais devem, no entanto, contemplar os casos de anomalias na radiografia simples do tórax ou a presença de adenomegalias em TC abdominopélvica, embora alguns autores e guidelines a recomendem por rotina. ${ }^{1-5}$

Os marcadores tumorais, alfa-fetoproteína (AFP) e go- 
nadotrofina coriónica humana (beta HCG) devem ser avaliados antes da cirurgia, bem como o valor da desidrogenase láctica (LDH). Se elevados devem ser cuidadosamente monitorizados nas semanas que se seguem atendendo às suas semividas (AFP cinco a sete dias e HCG dois a três dias). Salienta-se que a beta-HCG pode estar elevada em 10\% a 20\% dos casos de seminoma puro, mas este tipo histológico com elevação de AFP deve ser considerado como tendo componente não seminomatoso e tratado como tumor misto de células germinativas. ${ }^{1-4,6}$

O exame anatomopatológico informando sobre o tipo de tumor, tamanho, presença ou ausência de invasão linfovascular, da rete testis ou da túnica albugínea em conjunto com as informações fornecidas pela imagiologia e marcadores tumorais, permitem o estadiamento da doença e a estratificação por grupos de risco: baixo risco ou alto risco no caso dos seminomas puros e risco baixo, intermédio ou alto no caso dos não seminomas. Esta avaliação é a base para identificar os doentes com indicação para tratamento complementar pós-orquidectomia.1-4,7

A orquidectomia inguinal radical é o procedimento de eleição com intuito de diagnóstico e primeira abordagem terapêutica, exceto nos casos de doença extensamente metastizada e sintomática, em que a quimioterapia inicial está indicada.

Na decisão de tratamento pós-cirurgia, dois grandes desafios se colocam:

- Não sobretratar doentes em estádio precoce, seminomas em estádio I, sobretudo na ausência de fatores considerados de risco (tamanho do tumor superior a 4 cm e invasão da rete testis) e para os não seminomas em estádio I, na ausência de fatores tidos de mau prognóstico (invasão linfovascular, índice proliferativo superior a 70\% e presença de carcinoma embrionário superior a 50\%). Estes casos podem ser submetidos a um programa de vigilância médica rigoroso, pois mesmo os que vierem a recair poderão ser tratados sem sofrer redução da taxa de sobrevivência7-9;

- Melhorar os resultados do tratamento da doença extensamente metastizada, em particular nas formas de pior prognóstico e que incluem doentes com tumores primários não seminomatosos do mediastino, doentes com doença disseminada e marcadores elevados e doentes que recidivam após quimioterapia. ${ }^{1-4,10}$

No global, trata-se de uma doença eminentemente curável, com taxas de sobrevivência aos cinco anos superiores a 95\% e na qual mesmo com doença avançada o objetivo a procurar é o da cura.

\section{MÉTODOS}

Os autores efetuaram um estudo retrospetivo de doentes com diagnóstico de TCG, baseado nos processos clínicos, registo em ficheiro de diagnósticos e registo em anatomia patológica.

Reviram todos os processos, desde o diagnóstico, até à última consulta de vigilância, ainda que ocorrida junto de outro médico ou instituição, a quem foi pedida a informação necessária. A avaliação estatística aqui reportada foi efetuada em dezembro de 2014, tendo o último doente um recuo de seis meses desde o diagnóstico e o primeiro de mais de 15 anos.

\section{RESULTADOS}

No total, foram tratados 33 doentes, dos quais 22 (66,6\%) nos últimos seis anos, entre 2009 e 2014 (Fig. 1).

\section{$\mathrm{N}^{\circ}$ Casos/Ano \\ Total 33 doentes $22(66,6 \%)$ últimos 6 anos}

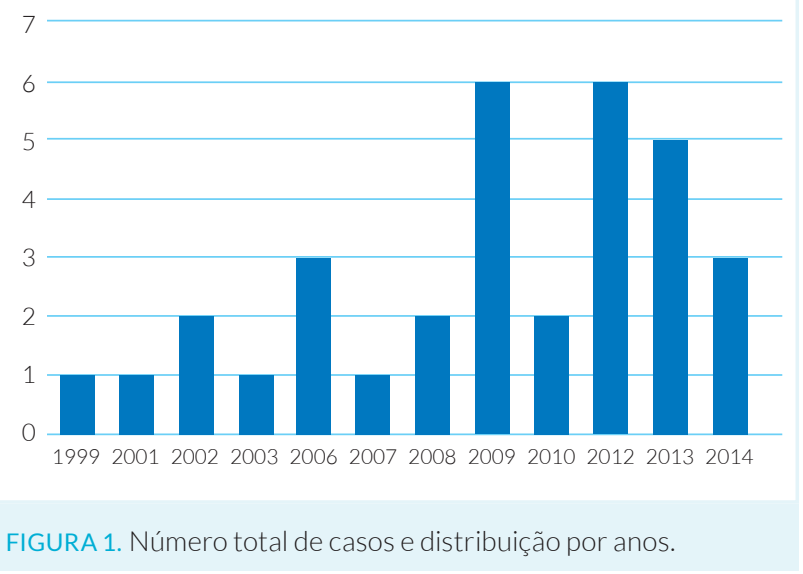

Histologias

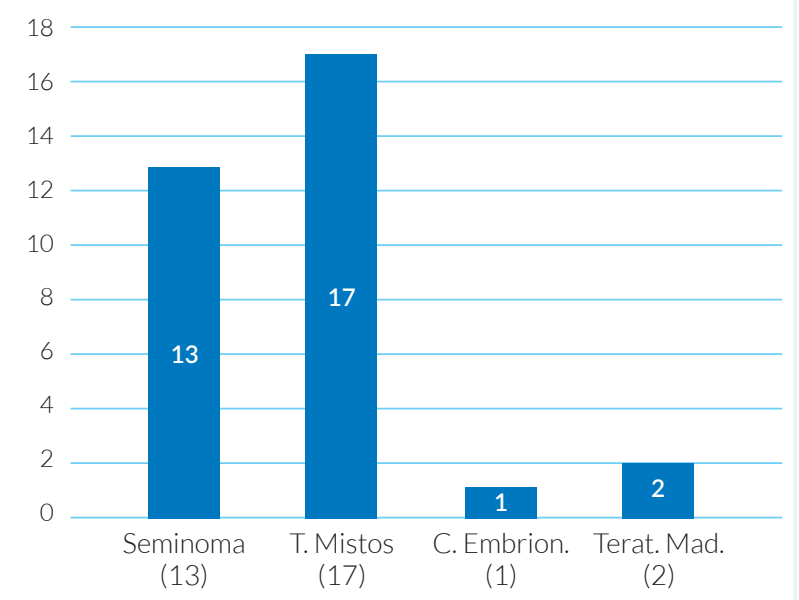

FIGURA 2. Distribuição do total de casos por tipo histológico. 
Os doentes tinham idades compreendidas entre os $15 \mathrm{e}$ os 58 anos, sendo a mediana à data do diagnóstico de 32 anos. Dos doentes, 72,7\% ( $n=24)$ tinham idades entre os 15 e os 35 anos. Em concordância com a literatura, a mediana de idades para seminoma foi de 35 anos e para não seminoma foi de 28 anos.

O diagnóstico de seminoma puro foi o tipo histológico predominante, sendo os restantes repartidos por tumores mistos, carcinoma embrionário e teratomas maduros (Fig. 2).

A distribuição por estádios mostrou 21 doentes (63,6\%) em estádio I, embora sete casos fossem estádios IS e noutros sete casos em estádio I, não houve avaliação pré-cirúrgica de marcadores tumorais (Fig. 3).

\section{Totais de Casos ( $n=33) /$ Estádios}

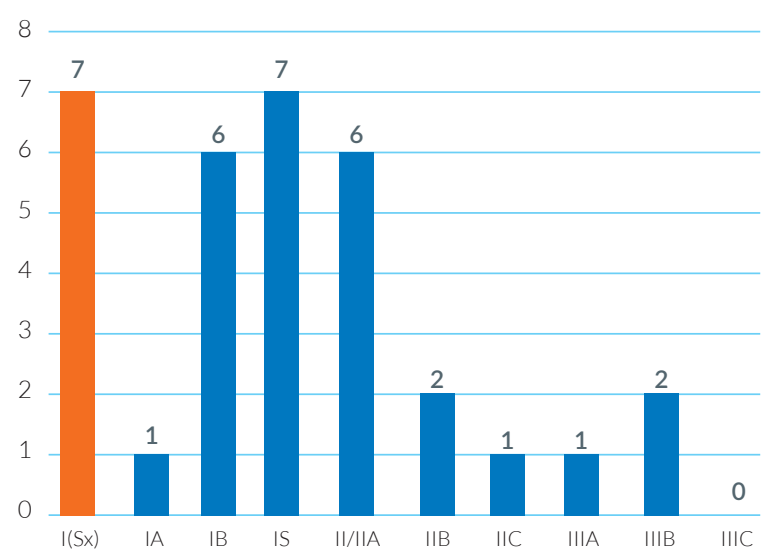

FIGURA 3. Distribuição por estádios do total de casos.

Marcadores Tumorais (Alfa-FP; Beta-HCG; LDH)

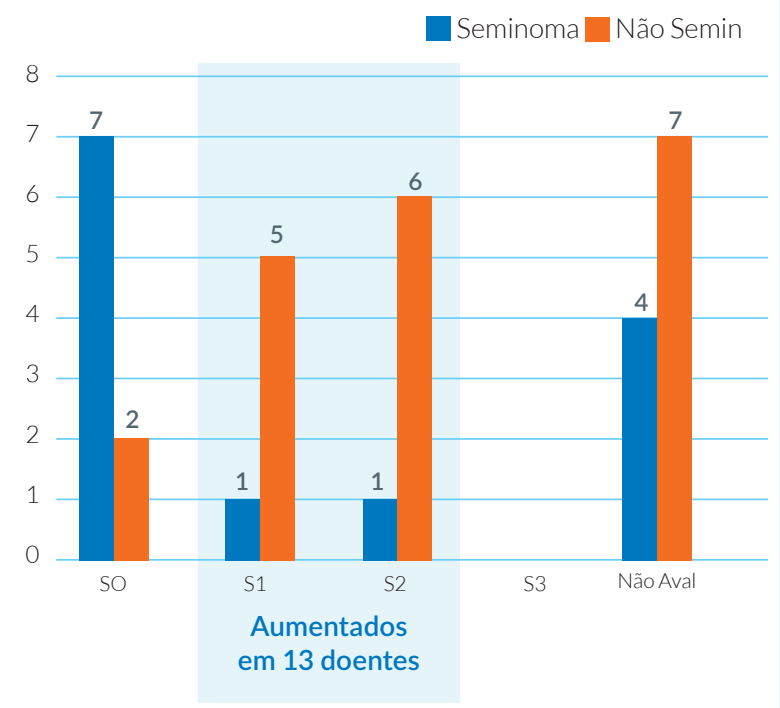

FIGURA 4. Resultados de marcadores tumorais no total dos casos.
Em estádios IA e IB (total de sete doentes), a repartição por seminomas versus não seminomas mostrou um predomínio do primeiro subtipo - um seminoma em estádio IA e quatro em estádio IB.

No que respeita aos marcadores tumorais e para todos os estádios, estavam aumentados em 13 doentes (39,3\%), incluindo dois casos de seminoma puro com aumento de beta-HCG (Fig. 4).

Descrevemos agora as características sumárias das doenças em estádio I, nomeadamente de acordo com a existência ou não de fatores de risco associados e tratamento versus vigilância no pós-cirurgia.

Estratificando estes tumores, de acordo com o subtipo histológico e fatores comummente referidos na literatura como conferindo pior prognóstico para os seminomas, tamanho do tumor (maior que $4 \mathrm{~cm}$ ) e a invasão da rete testis, encontramos um doente sem nenhum fator, um doente com presença dos dois fatores e os restantes cinco com pelo menos um fator de risco associado.

Destes sete doentes, apenas quatro fizeram tratamento pós-cirurgia: dois doentes com doença SX, quimioterapia com dois ciclos de carboplatina, um doente em estádio IB com um ciclo de carboplatina e um doente também em estádio IB fez radioterapia. Três doentes ficaram em vigilância pós-orquidectomia.

Para os não seminomas, e considerando como fatores de pior prognóstico em estádio I, a invasão linfovascular ou presença de componente de carcinoma embrionário em mais de 50\% do volume de doença, encontramos três doentes sem nenhum fator e nos outros quatro a presença de pelo menos um dos fatores de pior prognóstico.

Destes sete doentes, apenas três foram submetidos a quimioterapia com regime BEP no pós-orquidectomia, todos eles com doença contendo pelo menos um fator de risco. Um dos quatro doentes no grupo de maior risco, recusou tratamento complementar.

Em estádio IS (persistência de marcadores elevados, no pós-orquidectomia), foram encontrados um doente com seminoma (beta-HCG elevada) e seis doentes com tumores mistos.

Nenhum destes doentes tinha valores de marcadores S3. O doente com tipo histológico seminoma foi tratado com dois ciclos de carboplatina. Nos doentes com tumores não seminomatosos quatro doentes fizeram quimioterapia complementar. Nenhum doente foi submetido a dissecção ganglionar retroperitoneal.

Passamos agora a reportar os resultados dos doentes com doença clinicamente mais avançada. Por definição 
a doença clinicamente em estádio II tem adenomagalias regionais de tamanho superior a $1 \mathrm{~cm}$ na ausência de doença M1. O estádio III inclui qualquer T, qualquer $\mathrm{Ne}$ presença de doença M1 (M1a gânglios não regionais ou metástases pulmonares; M1b metastização à distância que não gânglios regionais ou pulmonares).

Nestes estádios, de doença clinicamente já metastizada pelo menos a nível ganglionar regional, há grupos de prognóstico bem definido para seminomas e não seminomas, como se mostra na Tabela 1. Os seminomas distribuem-se apenas por dois grupos de prognóstico bom ou intermédio e os não seminomas por três grupos, de prognóstico bom, intermédio ou mau. ${ }^{11}$

Todos estes doentes num total de 12, compreendendo estádios desde IIA, até IIIB (nenhum em estádio IIIC), foram tratados com quimioterapia, com regime BEP (bleomicina, etoposídeo e cisplatina). Um doente com tumor misto em estádio IIC, após três ciclos de BEP, por persistência imagiológica de doença ganglionar retroperitoneal, fez mais três ciclos de quimioterapia com regime TIP (paclitaxel, ifosfamida, cisplatina) e no final foi submetido a dissecção ganglionar retroperitoneal, não se tendo comprovado histologicamente persistência de doença, mas apenas fibrose.

Dos doentes com seminoma em estádio IIA (três casos), apenas um fez radioterapia para além de quimioterapia e nos casos de tumor não seminomatoso (três casos), nenhum fez dissecção ganglionar retroperitoneal.

\section{DISCUSSÃO}

A maioria das recidivas em TCG verifica-se no primeiro ano que se segue ao diagnóstico (cerca de 80\%) e as restantes no segundo ano, sendo raras as recidivas que ocorrem para lá desse tempo. A vigilância rigorosa de acordo com normas consensuais permite detetá-las em fase precoce, quando o tratamento rapidamente instituí- do permite resgatar de novo a maioria destes doentes. ${ }^{12}$

Nesta série de 33 doentes, verificaram-se quatro recidivas (12,1\%):

1. Seminoma puro em estádio IB, sem tratamento pós-orquidectomia, recidivado em gânglios retroperitoneais aos 22 meses após diagnóstico; foi detetado por aparecimento de lombalgia e confirmado por TC; foi tratado com quatro ciclos de BEP, seguidos de radioterapia; está em segunda remissão há 163 meses;

2. Tumor misto de células germinativas, estádio IIA, bom prognóstico, tratado pós-cirurgia com três ciclos de BEP seguidos de três ciclos de regime TIP (paclitaxel, ifosfamida, cisplatina), por persistência de adenomegalias e de dissecção ganglionar retroperitoneal.

Recidivou aos 20 meses, em adenomegalias das cadeias inguinais detetadas em imagiologia de rotina durante a vigilância; tratado então com quatro ciclos de gemcitabina + oxaliplatina. ${ }^{13}$ Está em segunda remissão há 96 meses;

3. Seminoma puro em estádio IS, tratado pós-cirurgia com dois ciclos de carboplatina, recidivado aos três meses pós-diagnóstico, com nódulo pulmonar detetado em TC de vigilância, submetido a excisão. Está em segunda remissão há 102 meses;

4. Seminoma em estádio IIA, de bom prognóstico, tratado com BEP no pós-operatório e recidivado aos 20 meses em gânglios retroperitoneais detetados em TC de vigilância.

Tratado exclusivamente com radioterapia, entrou em segunda remissão que dura há 30 meses.

Nesta série, a mediana de tempo para a recidiva foi de 20 meses. À data da revisão dos presentes dados e com uma mediana de follow-up de 59 meses, todos os doentes estavam vivos, 29 em primeira remissão e quatro em segunda remissão, sem doença (Fig. 5).

TABELA 1. Grupos de risco em doença metastática de acordo com o International Germ Cell Cancer Collaborative Group (IGCCCG).

\begin{tabular}{|c|c|c|}
\hline Classificação & Seminomas & Não seminomas \\
\hline Bom prognóstico & $\begin{array}{l}\text { Qualquer localização primária e ausência } \\
\text { de metastização visceral extrapulmonar e } \\
\text { AFP normal, qualquer HCG, qualquer LDH }\end{array}$ & $\begin{array}{l}\text { Tumor primário do testículo ou retroperitoneal. Ausência } \\
\text { de metástases pulmonares ou viscerais e AFP }<1000 \\
\text { mg/mL; HCG }<5000 \text { UI/L; LDH }<1,5 \times \text { LSN }\end{array}$ \\
\hline $\begin{array}{l}\text { Prognóstico } \\
\text { intermédio }\end{array}$ & $\begin{array}{l}\text { Qualquer localização primária e } \\
\text { metastização visceral extrapulmonar e AFP } \\
\text { normal, qualquer HCG, qualquer LDH }\end{array}$ & $\begin{array}{l}\text { Tumor primário do testículo ou retroperitoneal. Ausência } \\
\text { de metástases pulmonares ou viscerais AFP }>1000 \\
<10000 \mathrm{mg} / \mathrm{mL} \text {; HCG }<5000<50000 \mathrm{UI} / \mathrm{L} \text {; } \\
\mathrm{LDH}>1,5<10 \times \text { LSN }\end{array}$ \\
\hline Mau prognóstico & Não se aplica & $\begin{array}{l}\text { Tumor primário do mediastino ou } \\
\text { Metástases viscerais não pulmonares ou } \\
\text { AFP }>10000 \text { mg/mL; HCG }>50000 \mathrm{UI} / \mathrm{L} ; \mathrm{LDH}>10 \text { x } \\
\text { LSN }\end{array}$ \\
\hline
\end{tabular}




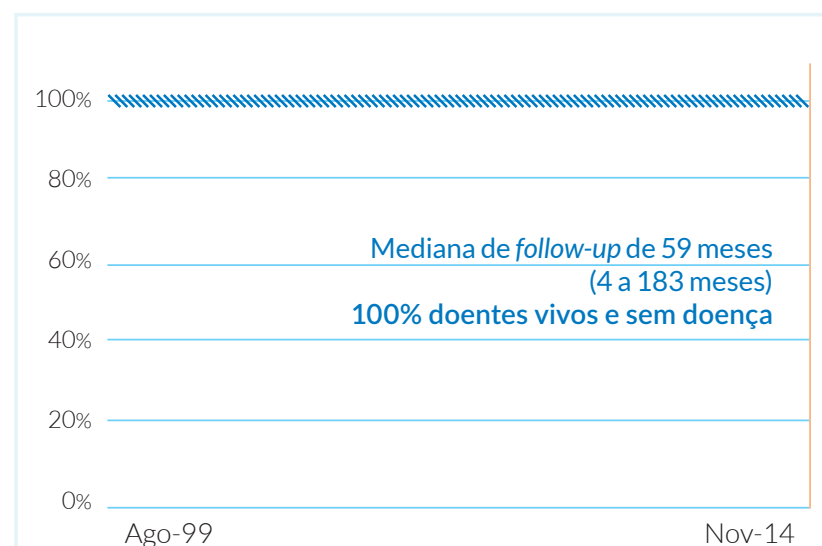

FIGURA 5. Sobrevivência global dos 33 doentes com mediana de seguimento de 59 meses.

Outras complicações relevantes a referir foram, rejeição da prótese testicular num caso e dois doentes submetidos a dissecção ganglionar tiveram complicações associadas a disfunção erétil e ejaculação retrógada. ${ }^{14}$ Todos os doentes submetidos a quimioterapia tiveram alopecia total e graus variáveis de anorexia, náusea, vómito, neurotoxicidade periférica reversível e citopenias. Nenhum teve qualquer complicação infeciosa associada a neutropenia, nem necessidades transfusionais em componentes sanguíneos.

Um doente, pela premência em iniciar tratamento citostático e dificuldade logística à data em fazer criopreservação de esperma, fez apenas uma administração de análogo LHRH previamente à administração de quimioterapia, com intuito de preservar as células germinativas no testículo restante. Tal procedimento não se veio a revelar eficaz, tendo o doente ficado azospérmico. ${ }^{15}$

Alguns dos doentes submetidos a tratamento citostático vieram mais tarde a ser pais de forma natural, não tendo sofrido toxicidade significativa sobre o testículo restante.

Um dos doentes submetido a radioterapia sobre cadeias ganglionares lombo-aórticas, teve durante meses sintomas e sinais de colite rádica.

\section{CONCLUSÃO}

Trata-se de uma revisão retrospetiva de uma série de doentes com TCG, de um único centro hospitalar e abrangendo um período de tempo alargado, de 15 anos. Há, assim, heterogeneidade na distribuição do número de casos ao longo deste tempo, confirmando-se um aumento do seu número nos últimos anos, havendo três anos, 2009, 2012 e 2013 em que foram tratados um total de 17 doentes, ligeiramente mais de metade do global.
Saliente-se de igual modo, a evolução do estado da arte no tratamento destas doenças ao longo deste período de tempo, em particular nas que se apresentam em estádio I, sem fatores de mau prognóstico associados e nas quais a opção pela vigilância médica rigorosa, veio provar que não diminui a taxa de sobrevivência global. Estes doentes se recaírem, podem ser salvos com tratamento adequado, mantendo as elevadas taxas de cura. ${ }^{7-9}$

Esta atitude de vigilância poupa muitos doentes a tratamentos desnecessários de quimio e radioterapia, evitando os eventuais efeitos secundários associados, a curto prazo a alopecia, citopenias, sintomas gastrointestinais, dermite rádica e a longo prazo a infertilidade e os segundos tumores entre outros. ${ }^{15,16}$

A análise desta série reflete o publicado na literatura médica, no que respeita à idade dos doentes, predomínio histológico e repartição por estádios e grupos de risco. Revela ainda assim um número excessivo de casos em que não há registo no processo clínico do valor de marcadores tumorais pré-cirurgia. A explicação mais plausível é de que nestes casos essa avaliação terá sido feita noutra instituição e não registada. Ocorre fundamentalmente nos primeiros anos.

De acordo com os conhecimentos e práticas atuais, a opção de tratar alguns dos doentes em estádio IA/IB, em particular com histologia de seminoma puro parece-nos discutível. Quando tratados, a opção foi maioritariamente por carboplatina em monoterapia, cujos resultados face a radioterapia na prevenção da recidiva não são inferiores. ${ }^{8,17}$

Em tumores não seminomatosos, em estádio IA, as alternativas de tratamento pós-cirúrgico incluem linfadenectomia retroperitoneal, quimioterapia (regime BEP) ou vigilância. A decisão de tratar versus vigilância rigorosa, depende entre outros fatores da presença ou não de critérios considerados de risco, nomeadamente invasão linfovascular. Em estádio IB, sobretudo na presença de invasão linfovascular em que a probabilidade de recidiva é de cerca de 50\%, quimioterapia adjuvante com regime BEP é recomendada, obtendo taxas de sobrevivência livre de recidiva superiores a 95\%.9,14

Nos doentes em estádio IS, a persistência de marcadores elevados sem evidência radiológica de doença, pressupõem a existência de doença micrometastática. Há, no entanto, falsos positivos, em particular com a beta-HCG, sendo necessário repetição frequente destes marcadores nas semanas que se seguem à cirurgia, para perceber a sua cinética. Em pelo menos dois dos casos de tumores mistos, não tratados com quimioterapia e com sobrevivências livres de recidiva de 68 e 48 meses, o estadia- 
mento inicial não estará provavelmente correto.

O doente mais intensivamente tratado, com um tumor misto de células germinativas em estádio IIC, submetido a dois regimes diferentes de quimioterapia (BEP $\times 3$ $>$ TIP $\times$ 3) e dissecção ganglionar retroperitoneal, mostrou que as imagens de persistência de adenomegalias do retroperitoneu em TC, correspondiam a fibrose e não a doença ativa.

Vem a recair meses depois, e para além da elevação de marcadores a TC deteta adenomegalias das cadeias ilíacas esquerdas. Faz então uma tomografia por emissão de positrões (PET), mas este não mostrou aumento de captação no local. Procedeu-se à excisão das massas ganglionares encontradas em TC e o exame anatomopatológico veio confirmar existência de doença, tendo voltado a fazer quimioterapia.

Este caso veio levantar a questão do valor da PET em TCG que está ainda em avaliação. Não há evidência atual que suporte a sua utilização no estadiamento inicial. Pode ser recomendado em doentes com seminomas em follow-up pós-quimioterapia e com massas residuais, para decisão de vigilância versus tratamento. Em não seminomas é mais questionável, não estando indicado no reestadiamento de tumores não seminomatosos, após quimioterapia. ${ }^{18,19}$

CONFLITOS DE INTERESSE: Os autores declaram não ter qualquer conflito de interesse na realização do presente trabalho.

FONTES DE FINANCIAMENTO: Não houve qualquer fonte de financiamento na realização do presente trabalho.

CONFIDENCIALIDADE DOS DADOS: Os autores declaram ter seguido os protocolos da sua instituição acerca da publicação dos dados de doentes.

PROTEÇÃO DE PESSOAS E ANIMAIS: Os autores declaram que os procedimentos seguidos na elaboração do presente trabalho estão em conformidade com as normas das comissões de investigação clínica e de ética, bem como da declaração de Helsínquia e da Associação Médica Mundial.

CONFLICTS OF INTEREST: The authors declare that they have no conflicts of interest.

FINANCIAL SUPPORT: This work has not received any contribution, grant or scholarship.

CONFIDENTIALITY OF DATA: The authors declare that they have followed the protocols of their work center on the publication of data from patients.

PROTECTION OF HUMAN AND ANIMAL SUBJECTS: The authors declare that the procedures followed were in accordance with the regulations of the relevant clinical research ethics committee and with those of the Code of Ethics of the World Medical Association (Declaration of Helsinki).

\section{REFERÊNCIAS}

1. Oldenburg J, Fosså SD, Nuver J, Heidenreich A, Schmoll HJ, Bokemeyer C, et al. Testicular seminoma and non-seminoma: ESMO Clinical Practice Guidelines for diagnosis, treatment and follow-up. Ann Oncol. 2013;24 Suppl 6:vi125-32.

2. NCCN Clinical Practice Guidelines in Oncology [accessed April 2017] Available from: https://www.nccn.org/professionals/physician_gls/f_guidelines.asp.

3. Albers P, Albrecht W, Algaba F, Bokemeyer C, Cohn-Cedermark G, Fizazi K, et al. Guidelines on Testicular Cancer: 2015 Update. Eur Urol. 2015;68:1054-68.

4. Krege S, Beyer J, Souchon R, Albers P, Albrecht W, Algaba F, et al. European consensus conference on diagnosis and treatment of germ cell cancer: a report of the second meeting of the European Germ Cell Cancer Consensus group (EGCCCG): part I. Eur Urol. 2008;53:478-96.

5. See WA, Hoxie L. Chest staging in testis cancer patients: imaging modality selection based upon risk assessment as determined by abdominal computerized tomography scan results. J Urol. 1993;150:874-8.

6. Germá Lluch JR, García del Muro X, Galán MC. Usefulness of tumor markers in the treatment of germ cell tumors. Arch Esp Urol. 2000;53:460-8.

7. Beyer J, Albers P, Altena R, Aparicio J, Bokemeyer C, Busch J, et al. Maintaining success, reducing treatment burden, focusing on survivorship: highlights from the third European consensus conference on diagnosis and treatment of germ-cell cancer. Ann Oncol. 2013;24 878-88.

8. de Wit R, Fizazi K. Controversies in the management of clinical stage I testis cancer. J Clin Oncol. 2006;24:5482-927.

9. TandstadT, Dahl O, Cohn-Cedermark G, Cavallin-Stahl E, Stierner $U$, Solberg A, et al. Risk-adapted treatment in clinical stage I nonseminomatous germ cell testicular cancer: the SWENOTECA management program. J Clin Oncol. 2009;27:2122-8.

10. Feldman DR, Bosl GJ, Sheinfeld J, Motzer RJ. Medical treatment of advanced testicular cancer. JAMA. 2008; 299: 67284.

11. The International Germ Cell Cancer Collaborative Group: International Germ Cell Consensus Classification: A prognostic factor-based staging system for metastatic germ cell cancers-International Germ Cell Cancer Collaborative Group. J Clin Oncol. 1997;15:594-603.

12. van As NJ, Gilbert DC, Money-Kyrle J, Bloomfield D, Beesley S, Dearnaley DP, etal. Evidence-based pragmatic guidelines for the follow-up of testicular cancer: optimising the detection of relapse. Br J Cancer. 2008;98:1894-902.

13. Pectasides D, Pectasides M, Farmakis D, Aravantinos G, Nikolaou M, Koumpou M, et al. Gemcitabine and oxaliplatin (GEMOX) in patients with cisplatin-refractory germ cell tumours: a phase II study. Ann Oncol. 2004;15:493-7.

14. Heidenreich A, Pfister D. Retroperitoneal lymphadenectomy and resection for testicular cancer: an update on best practice. Ther Adv Urol. 2012;4:187-205.

15. Martins M, Guimarães JM. Preservação da fertilidade em doentes oncológicos submetidos a terapêutica gonadotóxica. Rev Port Oncol. 2016;2:30-9.

16. Travis LB, Fosså SD, Schonfeld SJ, Aravantinos G, Nikolaou 
M, Koumpou M, et al. Second cancers among 40,576 testicular cancer patients: focus on long-term survivors. J Natl Cancer Inst. 2005;97:1354-65.

17. Oliver RT, Mason MD, Mead GM, von der Maase H, Rustin GJ, Joffe JK, et al. Radiotherapy versus single-dose carboplatin in adjuvant treatment of stage I seminoma: a randomised trial. Lancet. 2005;366:293-300.

18. Bachner M, Loriot Y, Gross-Goupil M, , Zucali PA, Horwich A, Germa-Lluch JR, et al. 2-1'?fluoro-deoxy-D-glucose positron emission tomography (FDG-PET) for postchemotherapy seminoma residual lesions: a retrospective validation of the SEMPET trial. Ann Oncol. 2012;23:59-64.

19. Hinz S, Schrader M, Kempkensteffen C, Bares R, Brenner W, Krege S, et al. The role of positron emission tomography in the evaluation of residual masses after chemotherapy for advanced stage seminoma. J Urol. 2008;179:936-40. 